\title{
Non-enteric adenovirus among children with gastroenteritis in Warri, Southern Nigeria
}

\author{
${ }^{* 1,2}$ Osazuwa, F., ${ }^{2}$ Johnson, W., and ${ }^{2}$ Grobler, H. S. \\ ${ }^{1}$ MDS Molecular Services, Sub-Saharan African Office, Jabi, Abuja, Nigeria \\ ${ }^{2}$ MDS Molecular Services, Johannesburg, South Africa \\ *Correspondence to: favourdesires@gmail.com; +2348100792725
}

Received Feb 17, 2021; Revised Apr 17, 2021; Accepted Apr 18, 2021

Copyright 2021 AJCEM Open Access. This article is licensed and distributed under the terms of the Creative Commons Attrition 4.0 International License <a rel="license" href="http://creativecommons.org/licenses/by/4.0/", which permits unrestricted use, distribution and reproduction in any medium, provided credit is given to the original author(s) and the source. Editor-in-Chief: Prof. S. S. Taiwo

\section{Adénovirus non entérique chez les enfants atteints de gastro- entérite à Warri, dans le sud du Nigéria}

\author{
$* 1,2$ Osazuwa, F., ${ }^{2}$ Johnson, W., et ${ }^{2}$ Grobler, H. S. \\ ${ }^{1}$ MDS Molecular Services, Bureau de I'Afrique subsaharienne, Jabi, Abuja, Nigéria \\ ${ }^{2}$ MDS Molecular Services, Johannesburg, Afrique du Sud \\ *Correspondance à: favourdesires@gmail.com; +2348100792725
}

Dear Editor,

Gastroenteritis is a major cause of mortality among children in Sub-Saharan Africa and in different parts of the world affected by poverty, malnutrition and poor health standards. Human adenovirus most especially the species belonging to HAdV-F types 40,41 , and HAdV-G type 52 are majorly implicated in childhood gastroenteritis (1), while other species are associated with respiratory disease, obesity and conjunctivitis (2). We here present an unusual finding of the detection of an adenovirus species potentially known to be associated with respiratory disease in the stool specimen of a child with gastroenteritis in Warri, South-South geopolitical region of Nigeria.

A cross-sectional study was conducted from March, 2018 to February, 2019. A total of 75 children with diarrhea from a pool of 356 , attending paediatric outpatient clinic of Central Hospital, Warri, South-South region, Nigeria, were randomly selected. The protocol for this study was approved by the Ethics and Research Committee of the Ministry of Health of Delta with reference numbers CHW/VOL14/130. Consent to participate in this study was obtained from each parent or guardian on behalf of the participants. Children with at least 3 episodes of diarrhea within 1 to 7 days, whose parents or guardians consented for their ward/children to participate were included in the study.

Stool specimens were collected into clean universal containers. The supernatants obtained from stool suspension of $50 \%$ in $1 \mathrm{ml}$ sterile phosphate buffered saline were stored at $-20^{\circ} \mathrm{C}$ for PCR assay of adenovirus. The stool specimens were initially screened for adenovirus using a rapid lateral flow immunochromatographic (LF-ICT) assay kit (Gastro Vir-Strip, Coris Bioconcept, Belgium). The result of this preliminary screening has been published (3).

DNA was extracted from all stool specimens of children positive for adenovirus by the LF-ICT assay (11/75) using QIAamp DNA stool kit (Qiagen, Germany) according to the manufacturer instructions, and stored at $-20^{\circ} \mathrm{C}$ till time of amplification. The primer pairs used for real-time PCR of the partial gene regions of the viral capsid genes, were Ad-1 (5'-TTCCCCA TGG CICAYAACAC-3') and Ad-2 (5'-CCCTGGTA KCCR ATRTTGTA-3'). The PCR cycling program was as follows; $94^{\circ} \mathrm{C}$ for $4 \mathrm{~min}$, followed by 35 cycles of $94^{\circ} \mathrm{C}$ for $30 \mathrm{sec}, 55^{\circ} \mathrm{C}$ for $30 \mathrm{sec}$, and $72^{\circ} \mathrm{C}$ for $1 \mathrm{~min}$ and a final extension cycle at $72^{\circ} \mathrm{C}$ for $7 \mathrm{~min}$. The amplicons were purified using the QIAquick PCR purification kit (Qiagen Inc., Valencia, CA). Nucleotide sequencing was done using Big Dye Terminator v 3.1 Cycle sequencer 


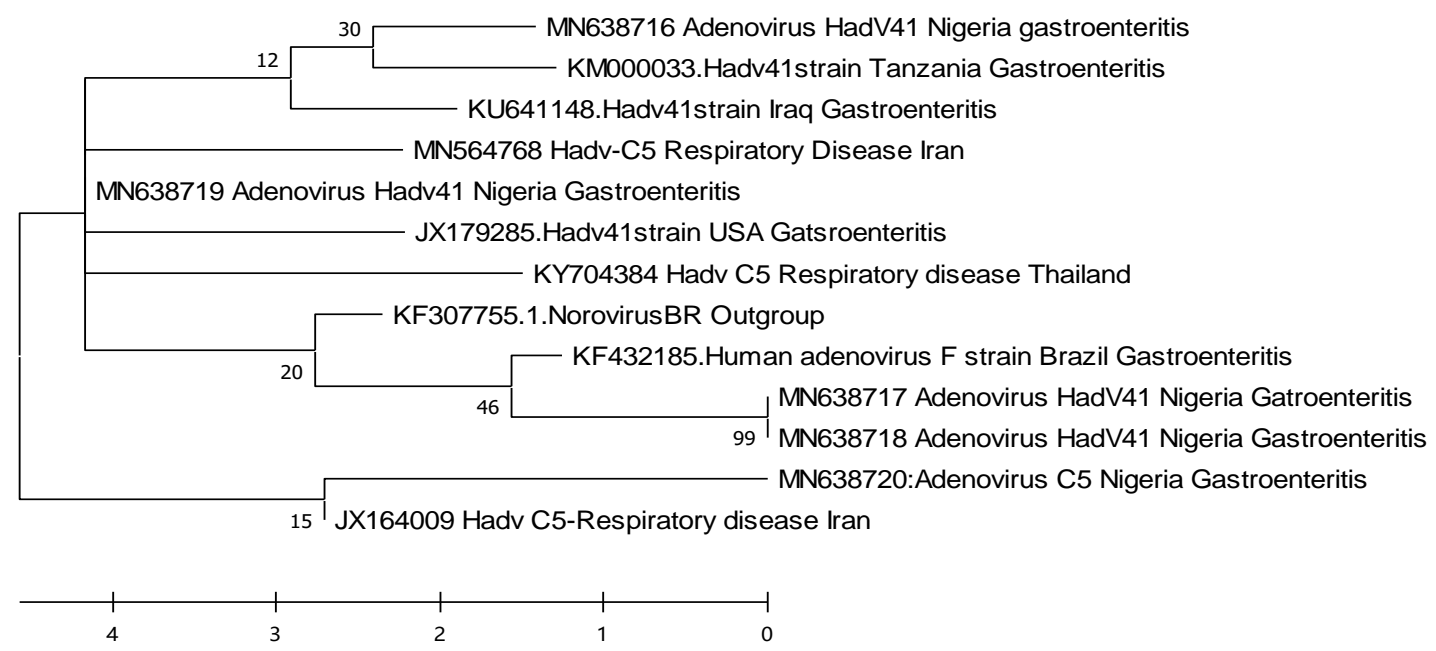

Fig 1: Phylogenetic tree of human adenovirus detected among children in Warri, Southern-Nigeria

(Applied Biosystems, Carlsbad, CA) on 3130 DNA genetic analyzer (Applied Biosystems, Carlsbad, CA), and sequences were edited using sequencher ${ }^{\circledR}$ version 5.4.6 DNA sequence analysis software (Gene codes Corporation, Ann Arbor, MI, USA). Phylogenetic analysis of the detected human adenovirus was conducted using the MEGA $X$. All HAdv nucleotide sequences obtained in this study were deposited into National Centre for Biotechnology Information (GenBank: http://www.ncbi.nlm.nih.gov/) under the accession number MN638716-MN638720.

Five of $11(45.0 \%)$ children were positive for HAdv on PCR. The report of phylogenetic analysis shows that 4 of the HAdv (MN638716MN638719) clustered with the well-known HAdv genotype responsible for majority of HAdv associated gastroenteritis, HAdv F 41 (Fig 1). It was observed that one of the HAdv detected (MN638720) clustered with HAdv C 5, an HAdv genotype usually detected in patients with respiratory disease.

The finding of non-enteric HAdv species among children with diarrhea has been reported in previous studies in other countries $(4,5,6)$. This study shows that non-enteric HAdv may also play a potential role in childhood gastroenteritis in our study area. A major limitation of this study was the small sample size. Large sample size would have help establish the frequency of detection of non-enteric genotypes of HAdv among children with gastroenteritis in our study area. Further studies involving a large sample pool is advocated.

\section{Acknowledgements:}

The authors appreciate MDS molecular Services, South Africa and DNA Labs Kaduna for assistance with laboratory analysis.

\section{Funding:}

Authors received no external funds.

\section{Authors' contribution:}

This study is part of the first author's doctoral thesis in Medical Molecular Biology, University of Benin, Benin City.

\section{References:}

1. Jones, M. S., Harrach, B., Ganac, R. D., et al. "New adenovirus species found in a patient presenting with gastroenteritis". J Virol.2007; 81 (11): 5978-5984.

2. Voss, J. D., Atkinson, R.L, and Dhurandhar, N. V. "Role of adenoviruses in obesity". Rev Med Virol. 2015;25 (6):379387

3. William, J. Q., and Osazuwa, F. Prevalence of Adenovirus among Children with Gastroenteritis/Diarrhea in Warri, Delta State, Southern, Nigeria. Int J Pediatr. 2018; 6 (5): 76517652

4. Kumthip, K, Khamrin, P., Ushijima, H., and Maneekarn, $\mathrm{N}$. Enteric and non-enteric adenoviruses associated with acute gastroenteritis in pediatric patients in Thailand, 2011 to 2017. PLoS One. 2019; 14(8): e0220263.

5. Afrad, M. H., Avzun, T., Haque, J., et al. Detection of enteric- and non-enteric adenoviruses in gastroenteritis patients, Bangladesh, 2012-2015. J Med Virol. 2018; 90 (4): patients,
$677-684$.

6. Moyo, S. J., Hanevik, K., Blomberg, B., et al. Prevalence and molecular characterisation of human adenovirus in diarrhoeic children in Tanzania; a case control study. BMC Infect Dis. 2014; 14:666. 